\title{
A current review of avian influenza in pigeons and doves (Columbidae)
}

\section{Celia Abolnik *} Department of Production Animal Studies, Faculty of Veterinary Science, University of Pretoria, Private
Bag X04, Onderstepoort, Pretoria 0110, South Africa

Keywords:

Avian influenza

Pigeons

Doves

Susceptibility

Transmission

\section{A B S T R A C T}

Recent reports of the detection of the zoonotic low pathogenic avian influenza (LPAI) H7N9 viruses in healthy pigeons have again put the spotlight on the potential role of pigeons and doves in the transmission of avian influenza between infected poultry and humans. A surge in studies followed the highly pathogenic avian influenza (HPAI) H5N1 epidemic, and this review collates the new data on AIV in pigeons and doves, both from a surveillance perspective, as well as the results of numerous clinical studies. Collectively, results of 32 field studies representing 24 countries across four continents indicate an antibody prevalence of $8.01 \%$ in pigeons and doves but only $0.37 \%$ of the total was associated with exposure to the same serotype as a highly pathogenic avian influenza (HPAI) outbreak occurring in poultry at the time. Only $1.1 \%$ of 6155 columbids sampled tested positive for Lle virus, dild unly 9/6155 (0.15\%) viruses were delected in regions Llal were experiencing outbreaks of a notifiable serotype at the time.

In 22 experimental infection studies with HPAI and LPAI viruses since 1944, only $26 / 715$ (3.64\%) mortalities were reported, and these could usually be associated with excessive doses of inoculum, which would induce fatal inflammatory responses. Since seroconversion and virus detection was demonstrated in many of these studies, albeit without clinical signs in most cases, it is clear that columbids are susceptible to infection, but ineffective propagators and disseminators of the virus, i.e. "dead end" hosts for AIVs, even HPAI. Viruses are shed in minute quantities from both the choana and in the feces for a short duration but titers are below the minimum threshold require to infect other species.

\section{Contents}

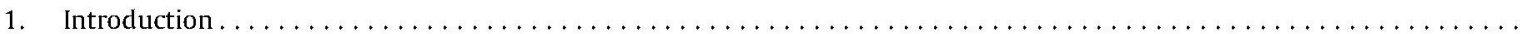

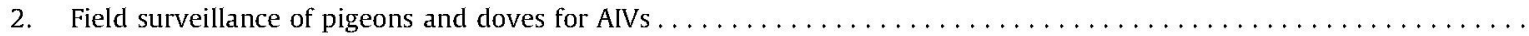

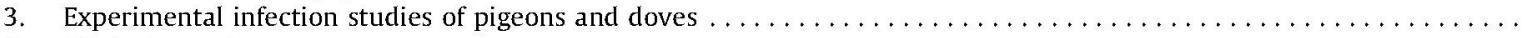

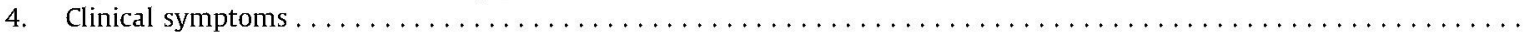

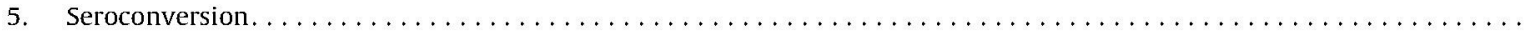

6. Viral shedding and transmission to sentinel birds: implications for columbids as "bridge species". . . . . . . . ....... 000

7. Possible mechanisms of innate resistance of pigeons and doves to AIV infection $\ldots \ldots \ldots \ldots$

\footnotetext{
* Tel.: +27 125298258 ; fax: +27 125298306 .

E-mail address: celia.abolnik@up.ac.za
} 


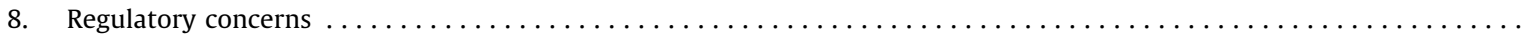

8.1. Artificial insemination as a route of AIV transmission in pigeons and doves . . . . . . . . . . . . . . . 000

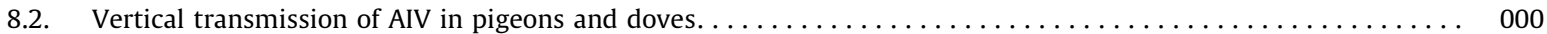

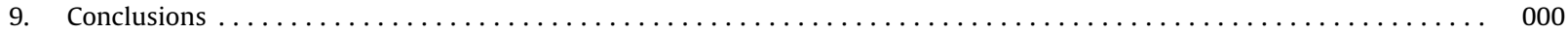

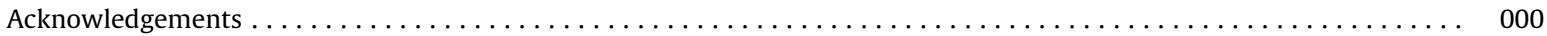

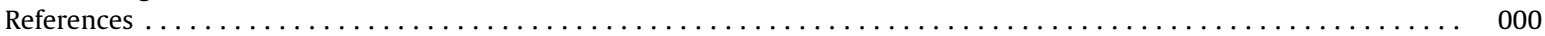

\section{Introduction}

Avian influenza is a serious disease of poultry and some mammals caused by certain serotypes of the influenza A virus (AIV), a member of the family Orthomyxoviridae. Ducks and shorebirds are the global natural hosts in which AIVs usually cause sub-clinical infections (Alexander, 2000). Serotypes are classified by the combination of two major antigens on the virion, namely hemagglutinin $(\mathrm{H})$ and neuraminidase $(\mathrm{N})$. Until recently, $16 \mathrm{H}$-types and nine $\mathrm{N}$-types were acknowledged, but a 17th and 18th $\mathrm{H}-$ type plus a 10th and 11th-N type were recently discovered in bats (Tong et al., 2012, 2013). AIV replicates in the respiratory and intestinal tracts of birds and infection typically follows the fecal-oral or aerosol route of transmission. Detection of the presence of viruses of the $\mathrm{H} 5$ or $\mathrm{H} 7$ serotypes in poultry or free-living birds are notifiable to the World Organization for Animal Health/ Office International des Epizooties (OIE) and are thus termed notifiable avian influenza (NAI), since the natural low pathogenic forms of $\mathrm{H} 5$ and $\mathrm{H} 7$ serotypes are prone to mutation in poultry to the highly pathogenic form (HPAI) that causes avian influenza (OIE, 2012a). Since a few exceptions to the aforementioned rule have been documented, notably with H10 serotypes, the disease avian influenza is defined as:

... an infection of poultry caused by any influenza A virus of the $\mathrm{H} 5$ or $\mathrm{H} 7$ subtypes or by any influenza $\mathrm{A}$ virus with an intravenous pathogenicity index ${ }^{1}$ greater than 1.2 (or as an alternative at least $75 \%$ mortality)...viruses can be divided into high pathogenicity avian influenza viruses (HPAI) and low pathogenicity avian influenza viruses (LPAI) (OIE, 2012a)

The pandemic caused by the avian-origin HPAI H5N1, arising in East Asia in 2003 and spreading westwards since 2005 to reach Europe and Africa, has infected at least 630 humans with 375 fatalities as of 4 June 2013. It remains endemic in Bangladesh, Cambodia, China, Egypt and Viet Nam (WHO, 2013). The potential role of wild birds in disseminating the disease westwards was a key research focus at the height of the epidemic (Breed et al., 2010). Pigeons and doves, members of the family Columbidae, have once again come under the spotlight for their potential role as bridge species in the ecology of avian influenza, i.e. their potential to transmit viruses between poultry and migratory waterfowl populations, or alternatively to transmit viruses

\footnotetext{
${ }^{1}$ The intravenous pathogenicity index (IVPI) is a clinical assessment of the virulence of AIVs in chickens. IVPI scores range from 0.0 (apathogenic) to a maximum of 3.0 (maximum pathogenicity) (OIE Terrestrial Manual, 2012).
}

between poultry sites during disease outbreaks. The latest global concern is a poultry-origin LPAI H7N9 strain, recently detected in healthy pigeons. As of 1 December 2013, this strain has already caused 139 laboratoryconfirmed human cases with 47 fatalities in China (Li et al., 2014).

Feral pigeons and doves naturally associate with environments where food, water and nesting sites are available, leading to close association with humans and poultry in cities and on farms. Pigeon racing is a popular and growing sport, increasingly so in East Asia, and a multi-million dollar industry. Large international races attract competitors from all over the world, with prizes of up to millions of United States dollars (\$) in prize money. Post-race auctions of winners for breeding purposes frequently fetch high prices, for example, the South African record price paid for a racing pigeon is over $\$ 80,000$ (South African Million Dollar Pigeon Race, http:// info.scmdpr.com). Birds imported internationally for races spend at least one month in quarantine in the race host country. When quarantine is lifted, pigeons begin their free-flight training and during this period they may come into contact with a variety of other wild birds and free-ranging poultry and contaminated environments. The OIE Terrestrial Code (OIE, 2012b) provides international guidelines to Veterinary authorities regarding importation of poultry and non-poultry avian species, their eggs, semen or other products. Racing pigeons are specifically excluded from the definition of "poultry" (Chapter 10.4, OIE, 2012b) with regard to control of infection with viruses of notifiable avian influenza (LPAI H5 or H7 or any other LPAI strain), but the immediate notification to the OIE of the detection of HPAI in any bird, including racing pigeons is prescribed.

All orders of birds have been demonstrated to be susceptible to infection with AIVs, but they display a spectrum of susceptibility as well as severity of symptoms according to the respective order. Gallinaceous poultry (chickens, turkeys, quail and guinea fowl) are considered to be highly susceptible to infection with HPAI strains, producing severe morbidity, mortality, gross and histological lesions. Ducks, gulls, starlings and pigeons are considered least susceptible, and display few or no clinical signs (Perkins and Swayne, 2003). Although some excellent reviews of AIV in pigeons and doves have been compiled in the past (e.g. Kaleta and Hönicke, 2004), a spate of new experimental infection and surveillance studies following the HPAI H5N1 epidemics have been published in subsequent years. This review collates the latest data and examines the cumulative results of studies conducted since the 1940s to consider the risks posed by columbids as reservoirs and vectors of AIV. 


\section{Field surveillance of pigeons and doves for AIVs}

The association of free-flying pigeons with urban areas, markets and farms where they are drawn by the availability of food, and their contact on poultry farms and in live bird markets with infected poultry have resulted in numerous targeted surveys to define their role in the ecology and transmission of AIV. Table 1 presents field surveillance data for columbids, both free-living and those from markets, listing species sampled, number of birds tested, the region and whether there were known outbreaks of HPAI in poultry in the vicinity at the time. The test method is indicated as either antibody or viral detection. Viral detection refers either to detection of the presence of viral RNA via molecular methods such as reverse-transcriptase PCR (RT-PCR) or inoculation into embryonated specific pathogen free (SPF) chicken eggs for virus isolation, or cell culture. Positive viral detection represents a current infection, whereas antibody detection methods (by agar gel precipitin, hemagglutination inhibition $[\mathrm{HI}]$ assay or blocking enzyme-linked immunosorbent assay [ELISA]), detect the presence of AIV-specific antibodies in blood serum and may indicate either a recent or a prior exposure to the virus.

Countries from four continents are represented in the cumulative surveillance results (Table 1). A total of 2046 apparently healthy columbids were sampled and tested for presence of AIV-specific serum antibodies, of which 164/ 2046 (8.01\%) were seropositive for AIV but only 3/811 (0.37\%) were identified as H5-specific specific antibodies that correlated with a $\mathrm{H} 5$ poultry outbreaks in the region at the time (Singsanan-Lamont et al., 2011). In fact, 818/2046 (40\%) of the samples in Table 1 had been collected in the vicinity of active NAI outbreaks in poultry at the time (South Africa, Germany and Thailand).

Numerous methods were used to detect serum antibodies in these studies. Some studies (Zupancic et al., 1986; Dovć et al., 2004; Khawaja et al., 2005; Dimitrov et al., 2010; Kohls et al., 2011) applied the OIErecommended HI method (OIE, 2012a). This standardized assay uses chicken red blood cells and viruses that are cultivated in chicken eggs as reagents. Chicken sera rarely give non-specific reactions, and the test is generally a sensitive assay in this specie, but sera of non-chicken species may produce non-specific agglutination reactions and thus pre-treatment steps are advised, specifically preadsorption of the columbid sera with chicken erythrocytes. In the aforementioned studies, $92 / 1082$ (8.5\%) of the columbid sera tested positive by the OIE-recommended HI method for AIV-specific antibodies. The outlier in this group is the study by Zupancic et al. (1986), accounting for all 92 positives, which were $\mathrm{H} 1$ serotype specific. These positives were from 92/391 urban pigeons sampled in Zagreb, and the authors suggest that the $\mathrm{H} 1$ serotype was transmitted from humans to pigeons, since none of the investigated free-ranging wood pigeons they investigated showed seroconversion (data not shown in Table 1). Interestingly, the AIV receptor profile of pigeons mimics those of humans, as discussed in a subsequent section.

Where the OIE method was cited as the serological test method, it was assumed that the pre-adsorption step was included to eliminate non-specific hemagglutinin reactions, but Mohammadi et al. (2010) specifically excluded pre-adsorption in their described HI method, resulting in $17 / 50$ (43\%) HI positive sera, which are possibly false reactors. One study applied the WHO-recommended HI method (2014) (Jia, 2007) which incorporates a receptordestroying enzyme (RDE) to eliminate false positive reactions, and 50/205 (24.39\%) HI positive sera were reported. bELISA detected 2/954 (0.21\%) seropositives, AGID $0 \%$, and a modified serum neutralization test 3/189 (1.5\%). If the results of the Zupancic and Mohammadi studies are excluded, the cumulative field seroprevalence of AIV in columbids declines to just 55/2046 (2.69\%), but it is likely that serological exposure to AIV was undermeasured in many of these studies because of differences in sensitivity between the various serological tests. Several of the experimental infection studies (Table 2) demonstrated this phenomenon.

In the viral detection studies, 6155 columbids were sampled (oropharyngeal, cloacal swabbing or organs from culls), of which only 68/6155 (1.1\%) were positive for AIV. Two of these viruses were isolated from pigeons found dead (Capua et al., 2000; Li et al., 2004; Songserm et al., 2006). 6/418 (1.4\%) LPAI H7N9 viruses were isolated from healthy pigeons in China during the current LPAI H7N9 outbreak (Zhang et al., 2013). The majority of samples, $4489 / 6155$ (72.9\%), were collected from columbids in regions experiencing NAI outbreaks in poultry at the time. A two-step nested RT-PCR assay detected a significantly higher AIV prevalence compared with virus detection by the other methods $(12 / 50 ; 24 \%$, Gronesova et al., 2009) followed by real-time RT-PCR $(13 / 1321 ; 1.92 \%)$, conventional RT-PCR (2/109; 1.83\%), and egg isolation (29/3882; $0.74 \%)$ but no viruses were detected using MDCK cell isolation systems $(n=189)$ or antigen detection kits $(n=26)$. Gronesova's explanation for the unusually high number of viral positives detected is the increased sensitivity of the nested typing RT-PCRs applied, however, in the personal experience of the reviewer, RT-PCRs for AIV targeting short genomic regions can yield false positive results that must be confirmed by amplicon sequencing, if not to exclude cross-contamination with the positive control used. This is especially important where the assay is not optimized, and no validation data was presented in the description of the method. On the other hand, the authors state that Slovakia is crossed by two dominant north-south and east-west bird migratory routes, and that urban pigeons may mix with these wild birds or come into contact with contaminated environments.

Since a variety of methods with variations in sensitivity and specificities were used, it is not possible to directly compare virus detection rates between different studies. RT-PCR is more sensitive than CEI because it detects viral genomic RNA fragments without a requirement for intact, infective viral particles. As an example in the difference in sensitivity, a 408/4820 (8.5\%) AIV prevalence in wild ducks sampled on the Texas Gulf Coast from 2005-2008 correlated to a $131 / 4820$ (2.7\%) prevalence on CEI for the same samples (Ferro et al., 2010). The use of CEI to screen columbid samples for AIV in the majority of cases probably resulted in an underrepresentation of true 
Table 1

Field surveillance of pigeons and doves for influenza A viruses.

\begin{tabular}{|c|c|c|c|c|c|}
\hline Specie & $\begin{array}{l}\text { Virus detected } \\
\text { [detection method] }\end{array}$ & $\begin{array}{l}\text { Antibody detected } \\
\text { [detection method] }\end{array}$ & Region & $\begin{array}{l}\text { HPAI in poultry in the vicinity } \\
\text { at the time of sampling }\end{array}$ & Reference \\
\hline Columba livia & $0 / 473$ & $\mathrm{n} / \mathrm{d}$ & USA & Yes, H5N2 & Nettles et al. (1985) \\
\hline Zenaida macroura & $\begin{array}{l}0 / 7 \\
{[\mathrm{CEI}]}\end{array}$ & & & & \\
\hline $\begin{array}{l}\text { Columba livia } \mathcal{E} \\
\text { Columba palumbus }\end{array}$ & $\mathrm{n} / \mathrm{d}$ & $\begin{array}{l}\text { 92/391 (23.3\%) [HI] } \\
\text { H1N? }\end{array}$ & Croatia & No & Zupancic et al. (1986) \\
\hline Columba livia & 0/54 [CEI] & $0 / 53[$ AGID] & New Zealand & No & Motha et al. (1997) \\
\hline Columba livia & $4 / 137[\mathrm{CEI}]$ & $\mathrm{n} / \mathrm{d}$ & China & Yes, H5N1 & Guan et al. (2000) \\
\hline Streptopelia decaocto & $\begin{array}{l}1 \mathrm{a} / 19(5.3 \%)[\mathrm{CEI}] \\
\text { HPAI H7N1 }\end{array}$ & $\mathrm{n} / \mathrm{d}$ & Italy & Yes, H7N1 & Capua et al. (2000) \\
\hline Columba livia & $\begin{array}{l}6 / 1190(0.5 \%)[\mathrm{CEI}] \\
\mathrm{H} 3 \mathrm{~N} 6, \mathrm{H} 9 \mathrm{~N} 2, \mathrm{H} 3 \mathrm{~N} 3\end{array}$ & $\mathrm{n} / \mathrm{d}$ & China & Yes, H5N1 & Liu et al. (2003) \\
\hline Columba livia & $0 / 139[\mathrm{CEI}]$ & 0/139 [HI] & Slovenia & No & Dovć et al. (2004) \\
\hline Columba livia & $\mathrm{n} / \mathrm{d}$ & $0 / 53[\mathrm{HI}]$ & South Africa & Yes, H5N2 & G. Akol (pers. comm.) \\
\hline Columba livia & $0 / 133$ [CEI] & $\mathrm{n} / \mathrm{d}$ & Australia & No & Peroulis and O'Riley (2004) \\
\hline Phaps calcoptera & $0 / 1$ & $\mathrm{n} / \mathrm{d}$ & & & \\
\hline Columba livia & $1^{\mathrm{a}} / 1$ [CEI] HPAI H5N1 & $\mathrm{n} / \mathrm{d}$ & Hong Kong & Yes, H5N1 & Li et al. (2004) \\
\hline Columba livia & $0 / 67[\mathrm{CEI}]$ & $\mathrm{n} / \mathrm{d}$ & Hong Kong & Yes, H5N1 & Ellis et al. (2004) \\
\hline Columba livia & $0 / 7[\mathrm{CEI}]$ & $0 / 7[\mathrm{HI}]$ & Pakistan & Yes, H7N3 & Khawaja et al. (2005) \\
\hline Columba livia & $0 / 200[$ CEI] & $\mathrm{n} / \mathrm{d}$ & Norway & No & Lillehaug et al. (2005) \\
\hline Columba livia & 1 $/ 1$ [CEI] HPAI H5N1 & $\mathrm{n} / \mathrm{d}$ & Thailand & Yes, H5N1 & Songserm et al. (2006) \\
\hline Streptopelia senegalensis & $11 / 78$ (not H5 or H7) & $\mathrm{n} / \mathrm{d}$ & Lebanon & No & Barbour et al. (2007) \\
\hline Gallicolumba spp. & $11 / 78$ (not $\mathrm{H} 5$ or $\mathrm{H} 7$ ) & $\mathrm{n} / \mathrm{d}$ & & & \\
\hline Columba livia & $\begin{array}{l}0 / 26 \\
\text { [antigen detection kit] }\end{array}$ & $\begin{array}{l}0 / 19 \\
{[\mathrm{bELISA}]}\end{array}$ & Nepal & No & Pant and Selleck (2007) \\
\hline Columba livia & $\mathrm{n} / \mathrm{d}$ & $\begin{array}{l}\text { 50/205 (24.4\%) } \\
\text { H9N? [HI with RDE] }\end{array}$ & China & Yes, H5N1 & Jia (2007) \\
\hline Columba livia & $0 / 6[C E I]$ & $\mathrm{n} / \mathrm{d}$ & Thailand & Yes, H5N1 & Amonsin et al. (2008) \\
\hline Columba livia & $0 / 50[\mathrm{CEI}]$ & $\mathrm{n} / \mathrm{d}$ & India & Yes, H5N1 & Pandit (2008) \\
\hline Columba livia & $\begin{array}{l}12 / 50(24 \%) \\
\text { H7N3, H9N5, H7N6, H14N8 } \\
\text { [2-step nested RT-PCR] }\end{array}$ & $\mathrm{n} / \mathrm{d}$ & Slovak Republic & No & Gronesova et al. (2009) \\
\hline Columba livia & $0 / 8$ & $\mathrm{n} / \mathrm{d}$ & Spain & No & Pérez-Ramírez et al. (2010) \\
\hline Columba palumbus & $0 / 8$ & $\mathrm{n} / \mathrm{d}$ & & & \\
\hline Streptopelia decaocto & $\begin{array}{l}0 / 15 \\
\text { [rRT-PCR] }\end{array}$ & $\mathrm{n} / \mathrm{d}$ & & & \\
\hline Streptopelia decaocto & $0 / 45[\mathrm{CEI}]$ & $\mathrm{n} / \mathrm{d}$ & Ukraine & No & Kulak et al. (2010) \\
\hline Streptopelia decaocto & $0 / 25$ & 0 & Caribbean & No & Lefrançois et al. (2010) \\
\hline Zenaida aurita & $\begin{array}{l}0 / 17 \\
\text { [rRT-PCR] }\end{array}$ & 0 & & & \\
\hline Columba livia & $\mathrm{n} / \mathrm{d}$ & $0 / 5[\mathrm{HI}]$ & Bulgaria & No & Dimitrov et al. (2010) \\
\hline Columba livia & $\begin{array}{l}0 / 50 \\
{[\text { RT-PCR] }}\end{array}$ & $\begin{array}{l}17 / 50(34 \%) \\
\mathrm{H} 9 \mathrm{~N} 2\left[\mathrm{HI}^{\mathrm{b}}\right]\end{array}$ & Iran & No & Mohammadi et al. (2010) \\
\hline Columba livia & $0 / 408$ & 0/364 [AGID/bELISA/HI] & Germany & Yes, H5N1 & Kohls et al. (2011) \\
\hline Columba palumbus & $\begin{array}{l}0 / 170 \\
{[\mathrm{CEI} \text { and rRT-PCR] }}\end{array}$ & $\begin{array}{l}2 / 123(1.6 \%) \text { [bELISA] } \\
\text { not H5 or H7 }\end{array}$ & & & \\
\hline Columba livia & $\begin{array}{l}1 / 51(2 \%) \mathrm{H} 5 \mathrm{~N} ? \\
\text { [RT-PCR] }\end{array}$ & $\mathrm{n} / \mathrm{d}$ & Egypt & Yes, H5N1 & Kayali et al. (2011) \\
\hline $\begin{array}{l}\text { Columba livia E } \\
\text { Streptopelia chinensis }\end{array}$ & 0/189 & $\begin{array}{l}3 / 189(1.6 \%) \\
\text { H5? Imodified SNTl }\end{array}$ & Thailand & Yes, H5N1 & Singsanan-Lamont et al. (2011) \\
\hline
\end{tabular}




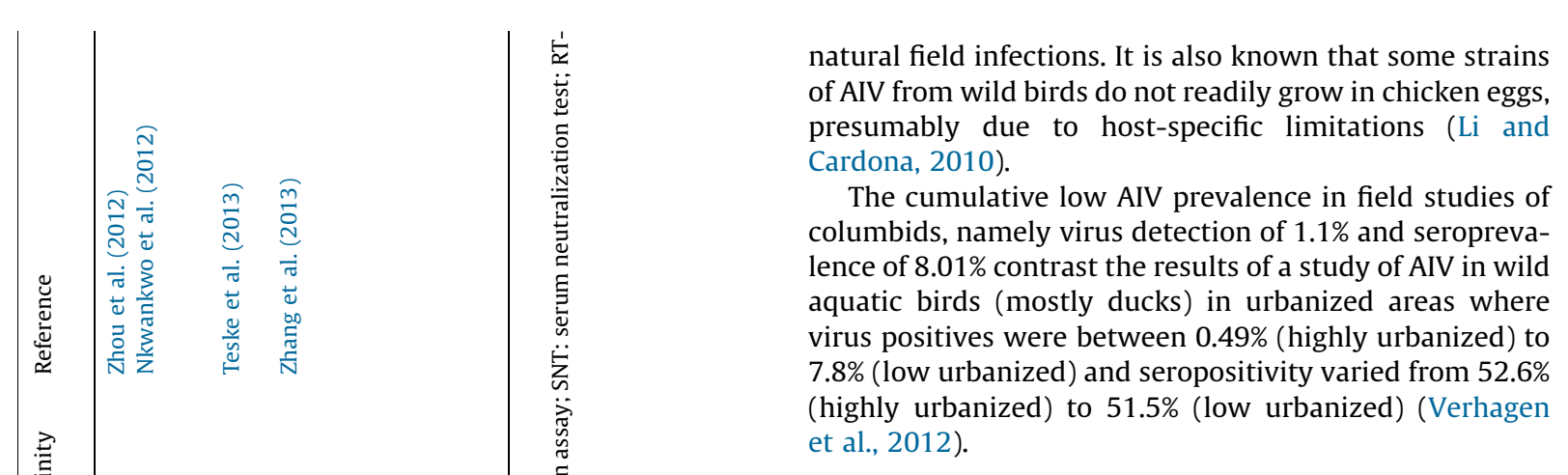

\section{Experimental infection studies of pigeons and doves}

Experimental infections of poultry and other birds with AIV are per regulations (OIE, 2012a) performed within high containment biosafety level 3 (BLS3) facilities, which cause additional stress to the birds due to the highly artificial environment and frequent handling. The studies listed in Table 2 generally aimed to assess the clinical symptoms induced by the strain in question, whether or not virus was shed via fecal or oral routes, which organ systems became infected, and the risk they posed in transmitting viruses to sentinel birds. Sentinels were either healthy pigeons or chickens housed with the inoculated birds. Different pathotypes (LPAI vs HPAI), serotypes (H5, H7 H6, H9) and clades within serotypes have been assessed over the years.

\section{Clinical symptoms}

For AIV to initiate infection, it should replicate in the epithelial cells at the site of entry. In the event of viral replication the progeny viruses will infect adjoining cells and may become viremic. Cell death, functional disturbances in organs, morbidity, production of antibody, and exit of the virus via the respiratory, conjunctival and intestinal secretions would occur in the course of infection (Panigrahy et al., 1996).

A total of 88 pigeons were inoculated with strains of LPAI and the only mortalities $(3 / 88 ; 3.4 \%)$ were recorded in a study in which immuno-suppression was chemically induced (Fang et al., 2006). All other pigeons experimentally infected with LPAI strains remained clinically healthy.

Cumulatively, 627 pigeons in 19 experimental studies were inoculated with strains of HPAI of varying doses, pathogenicity indices and clades, with only 23/627 (3.67\%) mortalities. In contrast, high mortalities were recorded in infected control chickens. In 13 of these studies representing $74.64 \%$ ( $n=468$ birds) of all pigeons inoculated with HPAI, no birds died, few displayed clinical symptoms, and if so recovered completely before the end of the trial. In contrast, $>75 \%$ of chickens inoculated with the same strains died within days of inoculation (Table 2). In the seven studies in which columbid mortalities were recorded (Slemons and Easterday, 1972; Kaleta and Hönicke, 2004; Klopfleisch et al., 2006; Yu et al., 2007; Brown et al., 2009; Hayashi et al., 2011a; Phonaknguen et al., 2013) mortalities were generally limited to one to two birds in each group, with the notable exceptions in the 
pathogenicity in controls

Number and

age of pigeons

A/FPV/Rostock/34 (H7N1; HPAI) $5 \%$ suspension of embryo membrane tissue, $1 \mathrm{ml}$ intramuscular A/turkey/Ontario/7732/66 (H5N9;

HPAI) $1 \times 10^{8}$ EID $_{50}$ per bird

intravenous and intranasal

A/turkey/Ontario/7732/66 (H5N9)

$10^{3.9}$ and $10^{5.1}$ EID $_{50}$ intranasal

$\mathrm{Pg} / \mathrm{HK} / \mathrm{FY} 6 / 99$ (H9N2)

Qa/HK/G1/97 (H9N2)

$\mathrm{Ck} / \mathrm{HK} / \mathrm{G} 9 / 97$ (H9N2)

$10^{6} \mathrm{EID}_{50}$ each, dose split between

intranasal, oral and orbital

A/Carduelis/Germany/72 (H7N1; HPAI)

EID $_{50}$ intramuscular for 11 pigeons and

$10^{8.1} \mathrm{EID}_{50}$ per bird conjunctival

A/chicken/Penn/1370/83 (H5N2; HPAI)

A/Chicken/Australia/32972/85

(H7N7; HPAI)

A/chicken/Penn/13609/93

(H5N2; LPAI)

A/emu/Texas/42499/93 (H7N1; LPAI)

$10^{5} \mathrm{EID}_{50}$ per bird, oculonasal and

intravenous

A/chicken/HK/220/97 (H5N1; HPAI).

$10^{6}$ EID $_{50}$ per bird, intranasal

A/chicken/HK/220/97 (H5N1; HPAI).

$10^{6} \mathrm{EID}_{50}$ per bird, intranasal

2003 outbreak strain, the Netherlands (H7N7; HPAI)

$10^{7} \mathrm{EID}_{50}$ per bird, intranasal

A/Carduelis/Germany/72 (H7N1; HPAI)

$\mathrm{EID}_{50}$ intramuscular

$10^{8.1}$ EID $_{50}$ conjunctival
Inoculated chickens died

3 adult pigeons

10/10 inoculated chickens

died within 5 days

Inoculated chickens died

pigeons

(2 groups)

$\mathrm{Qa} / \mathrm{HK} / \mathrm{G} 1 / 97$ and

$\mathrm{Ck} / \mathrm{HK} / \mathrm{G} 9 / 97$ did not

cause clinical signs in

chickens

Inoculated chickens died

9/12 chickens inoculated with HPAI strains died

High morbidity but no mortality in geese and emus inoculated

54/54 gallinaceous

species (chickens, quail, pheasants) inoculated died

IVPI $=2.94$

ICPI of 1.8. Control species inoculated developed serious clinical signs including neurological or died between 1 and $2 \mathrm{dpi}$ (chickens) and 5 and $6 \mathrm{dpi}$ (ducks) group pigeons $10^{2.1} \mathrm{EID}_{50}$ virus $10^{8.1} \mathrm{EID}_{50}$ virus turkeys, guinea fowl and
Experimental outcome

Reference $^{\mathrm{a}}$ adult contact pigeons per

11 adult pigeons, 2 adult pigeons, 2 adult contact

32 pigeons in total, 8 pe group for each virus and one mock inoculated group. 4 contact pigeons and chickens per group

4 week-old pigeons: 10 inoculated and 4 controls

4 week-old pigeons: 10 inoculated and 4 controls

15 pigeons, 3 contact pigeons added at $3 \mathrm{dpi}, 2$ uninfected controls

11 adult racing \& fancy pigeons inoculated with 2 adult show/homer pigeons inoculated with 2 adult American show racer pigeon contact controls
$2 / 3$ sick for 2 days; apathy, tremor, somnolence, both recovered, 1 pigeon had no signs

All birds remained healthy $21 \mathrm{dpi}$. No virus recovery from blood (CEI). HI titers in 4/4 birds ranging from 1:512 to 1:2048. Incontact turkeys did not seroconvert.

$1 / 19$ depressed and $1 / 19$ dead. $2 / 19$ virus isolated. $1 / 19 \mathrm{HI}$ positive

Virus detected in $2 / 4$ birds inoculated with $\mathrm{Ck} / \mathrm{HK} / \mathrm{G} 9 / 97$ by CEI on $1 \mathrm{dpi}$, in $1 / 4$ birds inoculated with Pg/HK/FY6/99 on $1 \mathrm{dpi}$. No spread to contact pigeons

1/11 developed conjunctivitis and tremor. 2/11 pigeons inoculated by the intramuscular route showed no signs but were $\mathrm{HI}$ positive. 2 contact pigeons showed no signs and were $\mathrm{HI}$ negative

No clinical signs or lesions in 32 pigeons by $21 \mathrm{dpi}$. 1/32 viruses recovered by $\mathrm{CEI}$ from LPAI H7N1 group, possible residual

inoculum cited. $0 / 32$ birds positive on $\mathrm{HI}$ tests, no clinical signs in contact birds

No signs, mortality, lesions or virus recovery (CEI). Serology not done

No signs, mortality, gross histological lesions or virus recovery (CEI). Serology not done

No clinical signs, CEI negative, 0/15 significant HI titers

Dinter (1944), cited by Kaleta and Hönicke (2004)

Nayaran et al. (1969)

Slemons and Easterday (1972)

Guan et al. (2000) and Guo et al. (2000)

Eckert (1979), cited by Kaleta and Hönicke (2004)

Panigrahy et al. (1996)

Perkins and Swayne (2002)

Perkins and Swayne (2003)

Shell (2004)

1 pigeon dead on $9 \mathrm{dpi}$; 3 pigeons with neck and body tremor, 4 pigeons with enteritis \& reduced body condition. Virus isolated from 1 pigeon at $9 \mathrm{dpi}$ (CEI). 7 showed no signs or lesions. 10/11 pigeons had $\mathrm{HI}$ titers of $1: 8$ to $1: 32$.

No signs, no lesions, no virus isolated, $2 / 2$ pigeons had $\mathrm{HI}$ titers of $1: 8$ to $1: 16$

No signs, no lesions, HI negative 
(H5N2; LPAI)
A/chicken/Taiwan/3152/03 (H6N1)

Both $5 \times 10^{6} \mathrm{EID}_{50}$, oculonasal route

\section{A/chicken/Indonesia/2003}

(H5N1; HPAI)

$10^{8} \mathrm{EID}_{50}$, ocular plus intranasal route
6N1-inoculated

chickens at 3 and 7 dpi by PCR. HI titers from $2^{6}$ to $2^{8}$

$5 / 5$ inoculated chickens died by 2 dpi
IVPI of 3.0 for each strain 3 dpi 49/49 control chickens inoculated died within
187 pigeons, 18 days to adult

64 4-week old pigeons, 8 groups of 8 pigeons, 1 negative control group
Cy-treated birds. All others including contact birds remained healthy. All pigeons, including dead ones negative on nested RTPCR (swabs and organs). No virus isolated (CEI), 0/20 pigeons HI positive

1 Cy-treated pigeon died on $3 \mathrm{dpi}$, all other pigeons remained clinically healthy. CEI negative, no nested RT-PCR positives, 0/24 pigeons $\mathrm{HI}$ positive

$5 / 14$ pigeons died on $5 \mathrm{dpi}$ ( 1 pigeon with neurological signs, subcutaneous hemorrhage, meningoenchephalitis of the cerebrum on histopathology), $7 \mathrm{dpi}$ ( 2 pigeons, depression and neurological signs, subcutaneous hemorrhage,

meningoenchephalitis of the cerebrum and brain stem on histopathology) or $19 \mathrm{dpi}$ ( 2 pigeons-euthanized following cerebral malacia, meningoenchephalitis and malacia of the cerebrum and brain stem on histopathology)

No clinical signs in 9 other pigeons. HI titers of $1: 32$ to $1: 64$ in 9/9 healthy pigeons, antibodies also detected by bELISA. Shedding via oropharynx and cloaca detected by rRT-PCR ranging from 13/16 on 2 dpi to 3/13 7 dpi. Virus isolation from organ pools in 2 healthy pigeons at 3 dpi. Sentinel chickens and pigeons kept with inoculated pigeons remained healthy and HI negative, rRT-PCR negative

No clinical signs.

No lesions apart from one swollen spleen

$2 / 187$ CEI positives in inoculated pigeons. $0 / 187$ pigeons positive on HI tests

$3 / 8$ deaths, MDT 4.3 days

2/8 deaths, MDT 5 days

$1 / 8$ deaths, MDT 6 days

$0 / 8$ deaths

$0 / 8$ deaths

$2 / 8$ deaths, MDT 5 days

$0 / 8$ deaths

Virus detected in all pigeon glandular stomach samples of all groups but not in all other organs (DAS ELISA). No serology performed.
Klopfleisch et al. (2006) and Werner et al. (2007)
(H5N1; HPAI)

(H5N1; HPAI)

IVPI $=2.96$

IVPI $=2.98$

(H5N1; HPAI)

A/chicken/Hubei/XFJ/2004

(H5N1; HPAI)

A/goose/Hubei/ZFE/2004 (H5N1; HPAI)

A/duck/Hubei/XFY/2004 (H5N1; LPAI)

All $10^{6}$ EID $_{50}$, intranasal 
Influenza A virus strain, dose and route of application

A/duck/Thailand/144/2005 (H5N1; HPAI)

A/quail/Thailand/144/2005

(H5N1; HPAI)

A/common magpie/HK/0138/2006 (H5N1; HPAI)

A/Japanese white-eye/HK/1038/2006 (H5N1; HPAI)

All $10^{6} \mathrm{EID}_{50}$, intranasal

A/Chicken/Anhui/85/2005 (H5N1; HPAI)

A/Chicken/Guangxi/12/2004

(H5N1; HPAI)

A/Chicken/Hubei/14/2004

(H5N1; HPAI)

A/Chicken/Tianjin/65/2004

(H5N1; HPAI)

A/Duck/Guangdong/23/2004

(H5N1; HPAI)

A/Duck/Hunan/15/2005 (H5N1; HPAI)

A/Pigeon/Hunan/39/2002

(H5N1; HPAI)

A/Pigeon/Jilin/30/2004 (H5N1; 2004)

A/Pigeon/Shanxi/47/2004

(H5N1; HPAI)

All $10^{6}$ EID $_{50}$, intranasal

A/Whooper swan/Mongolia/255/05 (H5N1; HPAI)

EID $_{50}$ (low dose)

$10^{4.9} \mathrm{EID}_{50}$ (medium dose)

EID $_{50}$ (high dose)

All intranasal

A/crested eagle/Belgium/01/2004

(H5N1; HPAI) clade 1

A/swan/Poland/305-135V08/2006

(H5N1; HPAI) clade 2.2

$10^{6}$ EID $_{50}$ each, oculonasa
Verification of viral pathogenicity in controls age of pigeons

Isolated from dead birds during HPAI outbreak; no chicken pathogenicity

data available. $66-100 \%$ of sparrows inoculated during same trial died within $4 \mathrm{dpi}$

A/pigeon/Hunan/39/2002 was isolated from a pigeon found dead (cause unknown). All other viruses were isolated from tissues of birds with

significant disease signs.

Adult Carneux pigeons, 3

pigeons inoculated pe group plus 2 contact

pigeons

160 7-week-old pigeons, 10 groups of 16 birds per group

House sparrows

inoculated were highly susceptible to even low doses, high viral titers excreted for several days prior to onset of clinical signs.

IVPI of 2.94

$5 / 5$ inoculated chickens died within $3 \mathrm{dpi}$

20 wild-caught adult rock pigeons; 4 groups of 5 birds per group

20 pigeons in two groups: 10 adults and 10 4-week-

old pigeons
Experimental outcome

Reference

No clinical symptoms observed in any pigeons, 0/12 mortalities, virus recovery from tracheal swabs on 3 and $5 \mathrm{dpi}$ from magpie virus inoculated pigeons (CEI), and from cloaca on $3 \mathrm{dpi}$ for quail isolate but trachea on $5 \mathrm{dpi}$ for this group. No seroconversion detected by $\mathrm{HI}$ in contact pigeons.
2/5 pigeons inoculated with high dose died at $7 \mathrm{dpi}$. Only one displayed clinical signs before death of weakness and lethargy and eventual neurologic signs before euthanasia, other was found dead without symptoms. Another bird in this group became mildly weak and lethargic at $6-8 \mathrm{dpi}$ but recovered fully. 2 other birds in this group remained healthy. $3 / 5$ seropositives in high dose group, 0/10 seropositives in medium plus low dose groups tested by AGP and bELISA. Viral shedding (CEI) brief and low with variation in site of shedding. No deaths or clinical signs in groups inoculated with low or medium doses

pigeons remained healthy over 14 day period, no gross lesions.

Microscopic lesions in organs of pigeons inoculated with clade 1 H5N1 found in lungs, trachea and kidneys. AIV-specific RNA detected from 3 to $10 \mathrm{dpi}$ in various tissues including lung, brain and heart by rRT-PCR. 3 oropharyngeal swabs weakly AIV positive at 3 and 7 dpi. 2 cloacal swabs at 5 and 7 dpi weakly AIV positive. $2 / 4$ sera positive on $14 \mathrm{dpi}$ on bELISA and $\mathrm{HI}(1: 16)$

RNA of Clade 2.2 virus detected by PCR in only one adult pigeon and $3 \mathrm{dpi}$ in trachea, lung, proventriculus and gizzard. No shedding detected on swabs, $0 / 4$ sera positive.

SPF contact pigeons remained healthy with no seroconversion or viral RNA detection
Brown et al. (2009)

Boon et al. (2007)

Jia et al. (2008) 
pigeons per group per virus/dose combination.

2 negative control pigeons plus 2 uninoculated control pigeons and 5 inoculated 3-wk old chickens controls

$0^{3}$ EID $_{50}$ (low dose)

$10^{6} \mathrm{EID}_{50}$ (high dose)

All intranasa

A/Pigeon/Thailand/VSMU-7-NPT/2004 (H5N1; HPAI, clade 1)

A/Tree sparrow/Ratchaburi/VSMU-

16-RBR/2005 (H5N1; HPAI, clade 1) $10^{6} \mathrm{EID}_{50}$ intranasal

\section{A/mallard/MN/436250/2000}

(H5N2; LPAI)

A/Ruddy turnstone/ReedsBeachNJ/00 (H7N3; LPAI)

$10^{6} \mathrm{PFU}$ intranasal
Isolated from a dead pigeon in 2004. 7/7

chickens inoculated died by $3 \mathrm{dpi}$

5/7 chickens inoculated died by $4 \mathrm{dpi}$; 2 survived to $10 \mathrm{dpi}$

$5 / 6$ chickens and 6/6 shed virus orally up until day 5 or 6

5/6 chickens and 6/6 blackbirds inoculated shed virus orally up until day 7 blackbirds inoculated total, 8 per group

12 wild-caught adult pigeons: 2 groups of 6 each
16 adult rock pigeons in pigeons infected with high dose of the 2007 strain (2-4 dpi with titers ranging from $10^{2.5} \mathrm{EID}_{50} / \mathrm{ml}$ to $10^{1.8} \mathrm{EID}_{50} / \mathrm{ml}$. One pigeon viscera harvested on $3 \mathrm{dpi}$ positive for virus isolation with titer of $10^{2.5} \mathrm{EID}_{50} / \mathrm{ml}$. Second pigeon harvested positive on 2 and $4 \mathrm{dpi}$ with titers of $10^{1.8} \mathrm{EID}_{50} / \mathrm{ml}$. Other swabs and visceral organs negative for isolation. No significant histopathological findings. 5 pigeons inoculated with high-dose ' 07 strain housed for 14 days with 5 contact chickens: All contact birds remained clinically healthy; 3 pigeons necropsied on 14 dpi showed

lymphoplasmacytic encephalitis, antigens detected in neurons and glial cells. HI antibody seroconversion was observed in both high-dose viruses ( $2 / 3$ and $1 / 3$; titers of $1: 16$ to $1: 32$ on $\mathrm{d} 14 \mathrm{pi}$ ) but $0 / 6 \mathrm{HI}$ positive in low dose groups. All chickens $\mathrm{HI}$ negative on 14 dpi.

Infection was established in $4 / 8$ pigeons inoculated with the ' 04 strain. Virus recovered from lungs, brain and tracheal swabs (CEI) with titers ranging from $10^{4.1}$ to $10^{5.5} \mathrm{EID}_{50} / \mathrm{ml}$. No virus recovered from 1 dead pigeon in this group. 2/6 pigeons seroconverted at 14 dpi with mean HI titer of 28 . 3/8 pigeons infected with ' 05 strain died at $14 \mathrm{dpi}$. $0 / 5$ seroconversion in 5 survivors at $14 \mathrm{dpi}$. No virus detected in 2 of the dead pigeons from this group In a second, similar experiment that included 8 sham-infected negative control pigeons, 2 pigeons in each group died by $14 \mathrm{dpi}$. No virus recovered from negative control group and no

seroconversion. Viral shedding and seroconversion in other groups.

$4 / 6$ survivors in infected groups seroconverted with mean HI titers of 24 and 57 for pigeon '04 and Tree sparrow '05 strains respectively. No viral shedding in survivors detected by $14 \mathrm{dpi}$. LPAI H5N2 virus: no clinical signs, virus recovered by MDCK plaque assay in $1 / 6$ pigeons from 1 to $3 \mathrm{dpi}$. $5 / 6$ bELISA positives but $0 / 6 \mathrm{HI}$ positives for inoculated pigeons, serology not done on contact pigeons.

LPAI H7N3 virus: no clinical signs, $1 / 6$ pigeons shed virus from days 1 to 3 (chicken and blackbirds when up to day 7) at $3.5 \log 10$ $\mathrm{PFU} / \mathrm{ml}$ as determined by plaque assay. $2 / 6$ inoculated pigeons sero-converted (bELISA) but $0 / 6 \mathrm{HI}$ positive. Contact pigeons: 5/6 bELISA positive and 0/6 HI positive.
Yamamoto et al. (2010.

Yamam
2012)

Hayashi et al. (2011a,b)

Achenbach and Bowen (2011) 


\begin{tabular}{lll}
\hline $\begin{array}{l}\text { Influenza A virus strain, dose } \\
\text { and route of application }\end{array}$ & $\begin{array}{l}\text { Verification of viral } \\
\text { pathogenicity in controls }\end{array}$ & $\begin{array}{l}\text { Number a } \\
\text { age of pig }\end{array}$ \\
\hline $\begin{array}{l}\text { A/Chicken/Thailand/vsmu-3/2004 } \\
\text { (H5N1; HPAI; clade 1) }\end{array}$ & $\begin{array}{l}30 / 30 \text { chickens inoculated } \\
\text { died from } 1 \text { to } 13 \text { dpi, } \\
\text { depending on dose }\end{array}$ & $\begin{array}{l}24 \text { adult p } \\
\text { groups of }\end{array}$ \\
$10^{1} \mathrm{TCID}_{50}$ & & \\
$10^{2} \mathrm{TCID}_{50}$ & & \\
$10^{4} \mathrm{TCID}_{50}$ & \\
$10^{5} \mathrm{TCID}_{50}$ & \\
$10^{6} \mathrm{TCID}_{50}$ & \\
All intranasal & \\
& \\
&
\end{tabular}

Antibodies detected in $1 / 4$ pigeons inoculated with $1 \times 10^{3} \mathrm{TCID}_{50}$, and in $4 / 4$ pigeons in all higher dose groups (in total 13/28 positives detected by modified HI using RDE and microneutralization tests. $1 / 4$ pigeons shed virus from choana for groups $10^{3}, 10^{4}$ and $10^{5} \mathrm{TCID}_{50}$ ranging from 2 to $21 \mathrm{dpi}$ (rRT-PCR). All birds inoculated with $10^{6} \mathrm{TCID}_{50}$ shed from the choana and cloaca for 8-18 dpi. $1 / 4$ pigeons shed virus from the cloaca in groups $10^{3}$, and $10^{5} \mathrm{TCID}_{50}$ ranging from 3 to $15 \mathrm{dpi}$ and 2 to $4 \mathrm{dpi}$ respectively. $2 / 4$ pigeons from group $10^{4} \mathrm{TCID}_{50}$ shed virus from cloaca from 3 to $15 \mathrm{dpi}$. No virus or antibodies detected in pigeons receiving doses of $10^{1}$ or $10^{2} \mathrm{TCID}_{50}$. Only $1 / 4$ pigeons in group $10^{5}$ and $2 / 4$ pigeons in group $10^{6} \mathrm{TCID}_{50}$ showed clinical symptoms (depression, ruffled feathers, sneezing, anorexia). All ill pigeons recovered apart from 2 in group $10^{6} \mathrm{TCID}_{50}$ that died $7-10 \mathrm{dpi}$
Phonaknguen et al. (2013)

.

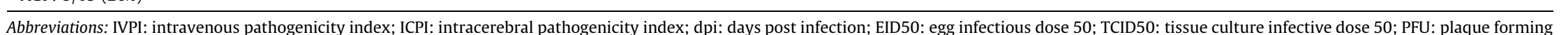

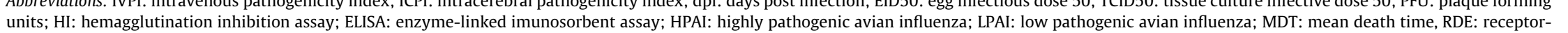

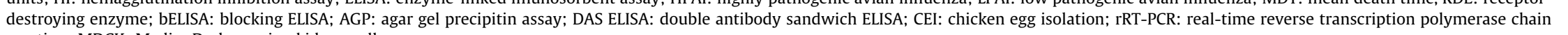
reaction; MDCK: Madin-Darby canine kidney cells. 
studies conducted by Klopfleisch et al. (2006), Yu et al. (2007) and Hayashi et al. (2011a). Hayashi and co-workers conceded that that the reason for the high mortalities observed (5/14 of pigeons dying within a two-week period) were probably due to environmental stress and not AIV infection, since two of these mortalities were in the sham-inoculated group.

None of the studies listed in Table 2 used "SPF" pigeons or doves (if indeed such a thing exists), so beyond appearing clinically healthy at the start of the experimental trials, the true infection status of these birds was unknown, and the presence of other concomitant pathogens that might have contributed to the severity of clinical signs or death cannot be ruled out. For example, Yamamoto et al. (2012) observed cases of intestinal capillariasis and coccidiosis in many pigeons including control birds during their experimental trials, considered incidental and unrelated to the viral infection.

During infection studies of pigeons with HPAI strains, lesions were observed or virus was detected in many organs including liver, pancreas, trachea, spleen, thymus, heart, bursa, proventriculus and intestine. Variations in severity of infection and duration were observed depending on the strain and inoculum dose (Yu et al., 2007; Jia et al., 2008; Brown et al., 2009; Smietanka et al., 2011; Phonaknguen et al., 2013). In contrast to the sporadic distribution and variability in severity of macro and microscopic lesions and virus detection in the aforementioned organ systems, most studies found that non-suppurative encephalitis is a characteristic finding in pigeons infected with the HPAI viruses, suggesting that the central nervous system in pigeons is frequently affected by this virus, even with asymptomatic infection (Yamamoto et al., 2012; Brown et al., 2009; Klopfleisch et al., 2006; Werner et al., 2007; Jia et al., 2008; Smietanka et al., 2011; Hayashi et al., 2011a; Phonaknguen et al., 2013). It has been suggested that in addition to paramyxovirus infection, HPAI should be included in the differential diagnosis when encephalitis is observed in pigeons (Yamamoto et al., 2012). It furthermore stands to reason that even though a pigeon may appear clinically healthy, is not shedding virus, but still has infected internal organs, that predators and scavengers are at risk of infection. The classic example is the case of a cat in Thailand that became infected and succumbed to HPAI H5N1 after consuming a pigeon carcass from which the virus was isolated (Songserm et al., 2006).

The only three studies that contradict the findings of the majority presented in Table 2 are those where excessive inoculation doses were used. In Klopfleisch and coworkers' study, 4/15 infected pigeons died following an inoculation dose of $10^{8} \mathrm{EID}_{50}$. High inoculation dose was also attributed to increased mortalities (2/5 pigeons; Brown et al., 2009) and increased morbidity without mortalities (Yamamoto et al., 2012). Why do high doses of viral inoculum induce disease but intermediate and low doses, although capable of establishing infection, do not? Studies in mice with AIV strains demonstrated that the immune system mounts a strong virus-specific and nonspecific cellular immune response involving the cyotoxic T-lymphocytes to even low exposure to the virus (Powell et al., 2006). A strong immune response is generated that is adequate to deal with the viral load reached 5 days after exposure to a small dose of virus, thereby curbing the spread of the virus and preventing clinical disease. However, after a large dose of the virus, the immune response is overwhelmed by the viral load reached at 5 days post inoculation (dpi). Increasing the dose of influenza virus increases the amount of measurable disease but does not affect the associated humoral immune response as dramatically (Powell et al., 2006; Moskophidus and Kioussis, 1998). These studies showed that the inflammatory process provoked during exposures to very high titers of AIV contribute to the pathology observed in mice, and this is likely to be the cause of increased pathology and mortalities in pigeons inoculated with excessive viral titers too. Inoculum dose may therefore be the single biggest contributing factor to high death rates in experimental infection studies in columbids, but Smietanka and co-workers (2011) reported a greater virus replication and lesion production potential of clade $1 \mathrm{H} 5 \mathrm{~N} 1$ compare to clade $2.2 \mathrm{H} 5 \mathrm{~N} 1$, even though clade 1 viruses did not result in the induction of noticeable clinical signs or death in infected pigeons, irrespective of their age. Yu et al.'s results (2007) also support the theory that strain differences to contribute to the severity of disease induced in pigeons. Genetic variations in AIV nucleoproteins, matrix proteins, non-structural proteins and the polymerase complex proteins of the viruses also contribute to host range and replication fitness (Liu et al., 2009).

\section{Seroconversion}

Unlike Table 1 field surveillance studies, it was possible for the investigators in Table 2 infection studies to use the homologous antigen as the test antigen in HIs, which would have improved the sensitivity of the assay. Despite this, only $4 / 386(12.19 \%)$ of sera tested by the OIErecommended method were $\mathrm{HI}$ positive, antibodies detected by bELISA were higher at 12/35 (34.28\%) and the highest seropositives were detected using HIs where receptor destroying enzyme was used as pre-treatment: $34 / 88$ (38.64\%). AGP detected 3/15 (20\%) positives. No serological positives were reported in the studies of Panigrahy et al. (1996), Shell (2004), Fang et al. (2006), and Liu et al. (2007), but all of these groups used the lesssensitive HI method. Antibodies were confirmed in 11 other studies listed in Table 2, proving that infection had been established, even though most of the birds remained clinically healthy.

It is possible that low levels of AIV-specific antibodies in columbids were not detected in many of the studies listed in both Tables 1 and 2. The HI method is the traditional method for identification of serotype-specific AIV antibodies in test sera. There is increasing data to suggest that the HI test lacks sensitivity for non-gallinaceous avian species when compared with results obtained using commercial nucleoprotein-based blocking ELISAs (Abolnik et al., 2013). bELISA Sample to Negative (S/N) ratios of 0.159-0.162 in pigeon sera are strong positive values, whereas on HI, the same samples' H5N1-specific HI titers were $1: 16$ (the threshold of positivity) using the homologous H5N1 virus and negative results were obtained with 
two other H5N1 viruses (Smietanka et al., 2011). Similarly, when Achenbach and Bowen (2011) monitored seroconversion to $\mathrm{AI}$ in pigeons, 5/6 (86\%) of birds had actually seroconverted according to the bELISA results whereas the $\mathrm{HI}$ titers were all negative. It is likely that the immune response of pigeons to AIV exposure been under-measured in many cases.

The consensus of the studies is that HPAI viruses can successfully infect pigeons and the majority report a general lack of clinical disease symptoms. Clinical symptoms and even mortality can be induced in pigeons by inoculating very high viral doses. Some H5N1 influenza viruses caused pathological changes in respiratory organs in early stages and invaded the brain in later stages, accompanying apparent lymphatic atrophy. Although infection efficiency varies among the strains used, the results of seroconversion suggest that infection is established in columbids even in temporal or non-efficient replication cycles.

\section{Viral shedding and transmission to sentinel birds: implications for columbids as "bridge species"}

For pigeons and doves to be considered a significant vectors in spreading virus between poultry, humans and migratory waterfowl, they would not only have to be easily infected but also be efficient replicators of the virus and shed the virus in high quantities either through the oropharyngeal route or via the feces. Surveys of free-flying birds across the world (Table 1 ) have already demonstrated that this is not the case in the field.

In the experimental infection studies (Table 2), viral shedding was assessed by firstly testing tracheal/choanal and cloacal swabs, or tissues from pigeons sacrificed during trials, or secondly (and perhaps more importantly) the inclusion of contact sentinel species. CEI was again the method of choice for viral detection in most studies. Experimental infections of columbids inoculated with low to moderate doses (Table 2) demonstrated that shedding levels have been generally low, ranging from $10^{2.8-3.4}$ EID $_{50}$ in tracheal and $10^{2.4-3.7}$ EID $_{50}$ in cloacal swabs (Hayashi et al., 2011a). The routes of viral shedding varied between individual pigeons and strains in most studies. Phonaknguen et al. (2013) used a quantitative RT-PCR approach to assess shedding routes and duration. Pigeons receiving a median dose of $10^{3} \mathrm{TCID}_{50}$ shed for up to $21 \mathrm{dpi}$ from both the choana and the cloaca, and furthermore the levels expressed as copies/ml $-1 \times 10^{6}$ were significantly lower in pigeons $(0.08 \pm 0.16$ and $0.65 \pm 0.13)$ compared to chickens receiving an even lower dose $\left(1 \times 10^{2} \mathrm{TCID}_{50}\right)$ $(84.42 \pm 10.76$ and $4.86 \pm 0.70)$.

Prior to 2011 (9 studies in total that incorporated sentinel birds), not a single contact/sentinel chicken, turkey or pigeon was demonstrated to seroconvert and/ or failed to shed virus, regardless of the AIV strain or dose received by the inoculated pigeons, suggesting that the shedding levels were below the threshold of the minimal infective particles required to infect other species. The two exceptions are the studies by Achenbach and Bowen (2011), where 5/6 contact pigeons were found to have seroconverted using bELISA ( $0 / 6$ of these were positive using $\mathrm{HI}$ ) but did not show any clinical symptoms, and the study of Phonaknguen et al. (2013). The latter reported the isolation from sentinel chickens of an HPAI strain administered at a dose of $1 \times 10^{6} \mathrm{TCID}_{50}$ to pigeons. The authors hypothesize that the reason for their results compared to all previous studies was insufficient time with close contact with the contaminated secretion shed through the choanal and cloaca. This seems unlikely to be the case though since chickens and pigeons were housed in close contact and shared the same food and water in other studies for up to three weeks in other studies (Werner et al., 2007; Liu et al., 2007; Smietanka et al., 2011). The pigeons were also purchased from a local Thai commercial pigeon farm and although the birds were demonstrated to be free of $\mathrm{H} 5$-specific antibodies by $\mathrm{HI}$ testing, no other pathogens were excluded. The limitations of HI screening have already been pointed out. By applying quantitative RT-PCR, they demonstrated in an experiment that sentinel chickens contracted H5N1 from inoculated pigeons (inoculation dose $10^{5} \mathrm{TCID}_{50}$ ). Choanal shedding in pigeons was $4.3 \pm 5.0$ copies $/ \mathrm{ml}-1 \times 10^{6}$ and detected from as early as $2 \mathrm{dpi}$ for Group 1 and $3.9 \pm 4.5$ for Group 2 with shedding from 4 dpi. Transmission to chickens occurred in both cases. These elevated "excretion" titers from the choana contrast sharply with cloacal shedding titers in these inoculated pigeons at $0.94 \pm 1.8$ and $0.24 \pm 0.06 \mathrm{copies} / \mathrm{ml}$ $-1 \times 10^{6}$ for the two groups, detected from $4 \mathrm{dpi}$ onward. The early detection of virus and elevated titers detected in the choana of inoculated pigeons raises concerns because it cannot be excluded that communal feed and drinking water was not contaminated by residual inoculum in the pigeons, resulting in the transmission to contact chickens.

Columbids with neuronal infections also discharged infectious viruses in oral or cloacal secretions, at low concentrations and for a brief duration, even in birds that became sick or died (Werner et al., 2007; Jia et al., 2008; Brown et al., 2009). The consensus remains that shedding levels in pigeons are below the threshold of the minimal infective particles required to infect other species.

\section{Possible mechanisms of innate resistance of pigeons and doves to AIV infection}

The first step in AIV infection is recognition and docking of the virus with specific host receptors on the cell surface. For AIVs, sialic acid (SA) molecules on the surface of epithelial cells are the binding targets of the viral hemagglutinin protein. The linkage of sialic acid to galactose, the species of sialic acid, and the anatomic distribution of sialic acids in the airways of animals all play important roles in determining the host's susceptibility and transmission efficiency of specific influenza viruses. Avianorigin AIVs have a preference for SA $\alpha 2,3 \mathrm{Gal}$ receptors. A number of avian and mammalian species that are highly susceptible to AIVs such as gallinaceous poultry, ducks, pigs, horses and others apparently predominantly carry $S A \alpha 2,3-$ Gal in the upper respiratory and gastrointestinal tracts. In contrast, humans have primarily SA $2,6 \mathrm{Gal}$ in the upper respiratory tract and are relatively insusceptible to AIV infection (Gambaryan et al., 1995). Liu et al. (2009) determined by lectin staining that the epithelial surfaces of the pharynx, trachea, bronchus and bronchiole of pigeons 
contained mainly SA $\alpha 2,6 \mathrm{Gal}$. Little or no SA 2 2,3Gal was found in the pigeon respiratory tract except in lung alveolar cells. The rectum of pigeons contained predominantly SA 2,3Gal. They proposed that AIV failed to replicate efficiently in pigeons and did not transmit virus to chickens infected experimentally due to the restriction in compatible receptor availability. The species of sialic acid NeuAc and NeuGc were experimentally demonstrated to play less of a role in establishing AIV infection in pigeons.

Lack of replication fitness of the virus in columbids, involving both host-specific co-factors (Moncorgé et al., 2010) and viral proteins of the replication complex (Wasilenko et al., 2008) would contribute to host resistance by restricting replication efficiency, and indeed Perkins and Swayne (2003) demonstrated a direct association between viral replication and the severity of disease in different avian hosts. Innate immune cell mechanisms are vital in controlling infections once the virus has achieved cell entry. Hayashi et al. (2011a) monitored cytokine responses in pigeons in response to infection with two HPAI H5N1 strains. They demonstrated that Pi04 replicated in the lungs more efficiently than T.Sparrow05, but did not induce excessive expressions of innate immune and inflammatory-related genes in the lungs of the infected pigeons. They postulated that pigeons could have tolerance toward Pi04 infection because of their moderate host cytokine responses following infection.

Tissue organ systems have proven useful in analysing local influenza virus growth characteristics in the presence of innate immune cell mechanisms. Petersen and coworkers (2012) demonstrated that LPAIV-infected pigeon tracheal organ cultures released significantly lower virus titers compared to the other bird species tested (chicken, turkey, Pekin duck) and did not reveal significant signs of infection-mediated ciliostasis in pigeons. Lectin staining of chicken, duck and turkey tracheas revealed the presence of both SA $\alpha 2,3 \mathrm{Gal}$ and SA 2 2,3Gal in the respiratory epithelium with $90 \%$ and $20-90 \%$ positive cells respectively, depending on the age and avian species. Since pigeon tracheas contain predominantly SA $\alpha 2,6$ Gal (Liu et al., 2009), Petersen and coworkers confirmed that, at least in part, the receptor differences contribute toward the "resistance" of columbids to AIV infections.

Species-related susceptibility or resistance is also dependent on differences in innate immune reactions. Barber and co-workers (2010) demonstrated that the retinoic acid-inducible gene I (RIG-I) is present in ducks but absent from chickens and plays a role in clearing an influenza virus infection. RIG-1 is a cytoplasmic RNA sensor, and triggering by influenza leads to production if interferon- $\beta$ and expression of downstream IFN-stimulated antiviral genes. Hayashi and co-workers (2011a) demonstrated that pigeons too possess a RIG-1 gene.

\section{Regulatory concerns}

\subsection{Artificial insemination as a route of AIV transmission in pigeons and doves}

The ability of LPAI viruses to infect chickens through other routes besides the intranasal route has been experimentally demonstrated: hens became infected with H6N2 through inoculation via the intracloacal as well as the intraoviduct routes. However, use of an H9N2 virus failed to establish infection in either of these routes, demonstrating the importance of strain in infectious route (Pantin-Jackwood et al., 2012). Due to the apparent innate ability of columbids to rapidly and efficiently curb AIV replication and infection, it seems unlikely that sufficiently high viral loads would be produced in pigeon semen to make this a significant route of infection, however further studies are required to clarify this. Article 10.4 .18 of the OIE Terrestrial Code sets guidelines in the importation of semen of avian species other than poultry from origin countries regardless of the NAI of that country. The Veterinary authority should require an international veterinary certificate attesting that the donor birds were kept in an approved isolation facility for at least 21 days prior to semen collection; that the donor birds showed no clinical sign of infection with a virus that could be considered to be NAI during the isolation period and that the pigeons were tested within 14 days prior to semen collection and shown to be free of NAI infection (OIE, 2012b).

\subsection{Vertical transmission of AIV in pigeons and doves}

Despite the fact that several experimental studies and reports of natural infections prove that vertical transmission occurs in gallinaceous poultry (Cappucci et al., 1985; Bean et al., 1985; Kilany et al., 2010; Promkuntod et al., 2006; Pillai et al., 2010), there is no evidence to suggest that this occurs in columbids, and no experimental infections to investigate transmission of AIV in pigeon or dove eggs are documented. This is a topic that requires experimental investigation for a conclusion, emphasized by the observation of mild sporadic microscopic lesions in the ovarial thecal epithelial cells of H5N1 inoculated rock pigeons (Brown et al., 2009). For the sake of caution the OIE (Article 10.4.12 OIE, 2012b) recommendation for the importation of hatching eggs from pigeons, regardless of NAI status of the country of origin, stipulate that the veterinary authorities require an international veterinary certificate attesting the following: the parent birds must be subjected to a diagnostic test seven days prior to and at the time of the collection of the eggs to demonstrate freedom from infection with NAI; the eggs have had their surfaces sanitized according to recommended guidelines and that the eggs are transported in new or appropriately sanitized packaging materials. If the parent birds have been vaccinated against NAI, proof that it has been done in accordance with the OIE Terrestrial Manual (OIE, 2012a) and full details of the nature and date of vaccine used must be attached to the certificate.

\section{Conclusions}

The camps remain divided on conclusions of the risks posed by columbids in HPAI ecology, ranging from questionable or negligible (Panigrahy et al., 1996; Perkins and Swayne, 2003; Liu et al., 2007; Boon et al., 2007; Brown et al., 2009; Smietanka et al., 2011; Kohls et al., 2011) to a 
potential source of infection to humans and other animals (Klopfleisch et al., 2006; Jia et al., 2008; Nkwankwo et al., 2012). Since columbids are mostly free-living (with the exception of those raised for meat and in live markets), the most pertinent question pertains to the probability that columbids are an efficient transmission or maintenance host for the intra- and inter-regional spread of the virus during outbreaks. The facts as they have emerged from the various studies are summarized as follows:

1. Columbids can and do become infected with AIVs in the field (as demonstrated by presence of antibodies and virus detection).

2. In experimental infection studies, infection in columbids can be induced using low to medium titers of virus, but the birds would usually not show clinical signs, even when infected with HPAI strains. "Resistant to infection" is a term that must be used with caution. Rather, they are susceptible to infection, but ineffective propagators and disseminators of the virus. A "dead end" host would be a more apt description.

3. Virus will be shed in minute quantities from both the choana and in the feces for a short duration but titers are below the minimum threshold require to infect other species.

4. Innate viral resistance mechanisms in columbids are at play. These represent enticing research avenues.

5. Where possible, the brain is the best sample for testing when AIV is suspected, even though the bird may not be clinically ill or shedding virus.

6. For serological detection, more sensitive methods such as cELISA, HI using RDE and DAS ELISA are recommended.

7. For virus detection, nested RT-PCR and real-time RTPCR are sensitive methods that may be used for screening and positives can be inoculated into eggs of cell culture systems.

8. Using excessive titers of HPAI virus $>10^{6}$ EID $_{50}$ in challenge experiments will induce clinical signs and death, but this is likely due to cellular damage from inflammatory processes.

9. Clade differences in viral replication fitness exist, even within serotypes, and must be taken into consideration.

10. Vertical transmission in columbids has not been experimentally investigated and this should be done to conclusively exclude this as an infection route, however unlikely it may seem.

Thus, any significant role that columbids may play in disseminating avian influenza is more likely to be via the mechanical route, as fomites on their feet and feathers by contaminated environmental sources, or scavenging of dead columbids. Suitable quarantine periods (Article 10.4.1 of the OIE Terrestrial code defines the incubation period of NAI to be 21 days) and proper biosecurity should mitigate any unforeseen risks for legally-traded pigeon imports with regard to avian influenza. However, AIV as a pathogen is notorious for evolving to adapt to new hosts and transmission mechanisms, and ongoing surveillance of columbids should be included in surveillance programs.

\section{Conflict of interest statement}

The author declares that there is no conflict of interest.

\section{Acknowledgements}

Marthinus Hartman is thanked for critical review of the manuscript. In memory of Zandy Meyer, who requested this review on behalf of the South African pigeon racing community.

\section{References}

Abolnik, C., Fehrsen, J., Olivier, A., van Wyngaardt, W., Fosgate, G.T., Ellis, C.E., 2013. Serological investigation of highly pathogenic avian influenza H5N2 in ostriches (Struthio camelus). Avian Pathol. 42 (3) 206214.

Achenbach, E., Bowen, R.A., 2011. Transmission of avian influenza A viruses among species in an artificial barnyard. PLoS ONE 6 (3) e17643.

Alexander, D.J., 2000. A review of avian influenza in different bird species. Vet. Microbiol. 74, 3-13.

Amonsin, A., Choatrakol, C., Lapkuntod, J., Tantilertcharoen, R., Thanawongnuwech, R., Suradhat, S., Suwannakarn, K., Theamboonlers, A., Poovorawan, Y., 2008. Influenza A virus (H5N1) in live bird markets and food markets, Thailand. Emerg. Infect. Dis. 14 (11) 1739-1742.

Barber, M.R., Aldridge Jr., J.R., Webster, R.G., Magor, K.E., 2010. Association of RIG-I with innate immunity of ducks to influenza. Proc. Natl. Acad. Sci. U.S.A. 3107 (13) 5913-5918.

Barbour, E.K., Shaib, H.A., Rayya, E.G., 2007. Reverse transcriptase-polymerase chain reaction-based surveillance of type A influenza viruses in wild and domestic birds of the Lebanon. Vet. Ital. 43 (1) 33-41.

Bean, W.J., Kawaoka, Y., Wood, J.M., Pearson, J.E., Webster, R.G., 1985. Characterization of virulent and avirulent A/chicken/Pennsylvania/83 influenza A viruses: potential role of defective interfering RNAs in nature. J. Virol. 54 (1) 151-160.

Boon, A.C., Sandbulte, M.R., Seiler, P., Webby, R.J., Songserm, T., Guan, Y., Webster, R.G., 2007. Role of terrestrial wild birds in ecology of influenza A virus (H5N1). Emerg. Infect. Dis. 13 (11) 1720-1724.

Breed, A.C., Harris, K., Hesterberg, U., Gould, G., Londt, B.Z., Brown, I.H., Cook, A.J., 2010. Surveillance for avian influenza in wild birds in the European Union in 2007. Avian Dis. 54 (1 (Suppl.)) 399-404.

Brown, J.D., Stallknecht, D.E., Berghaus, R.D., Swayne, D.E., 2009. Infectious and lethal doses of H5N1 highly pathogenic avian influenza virus for house sparrows (Passer domesticus) and rock pigeons (Columbia livia). J. Vet. Diagn. Invest. 21, 437-445.

Cappucci, D.T., Johnson, D.C., Brugh, M., Smith, T.M., Jackson, C.F., Pearson, J.E., Senne, D.A., 1985. Isolation of avian influenza virus (subtype H5N2) from chicken eggs during a natural outbreak. Avian Dis. 29 (4) $1195-1200$

Capua, I., Grossele, B., Bertoli, E., Cordioli, P., 2000. Monitoring for highly pathogenic avian influenza in wild birds in Italy. Vet. Rec. 147, 640.

Dimitrov, K.M., Manvell, R.J., Goujgoulova, G.V., 2010. Status of wild birds in Bulgarian zoos with regard to orthomyxoviruses and paramyxovirus Type 1 infections. Avian Dis. 54, 361-364.

Dinter, Z., 1944. Vergeleichende untersuchungen über die atypische und klassiche geflügelpest. Arch. Ges. Virusforsch. 3, 207-219.

Dovć, A., Zorman-Rojs, O., Vergles Rataj, A., Bole-Hribovsek, V., Krapez, U., Dobeic, M., 2004. Health status of free-living pigeons (Columbia livia domestica) in the city of Ljlubljana. Acta Vet. Hung. 52 (2) 219-226.

Eckert, A., 1979. Charakterisierung eines hämagglutinierenden agens aus einem erlenzeisig (Carduelis spinus)- Beitrag zur ätiologie einer erkrankung von sperlingvögeln (Passeriformes). Vet. Med. Diss. Hannover.

Ellis, T.M., Bousfield, R.B., Bissett, L.A., Dyrting, K.C., Luk, G.S.M., Tsim, S.T., Sturm-Ramirez, K., Webster, R.G., Guan, Y., Peiris, J.S.M., 2004. Investigation of outbreaks of highly pathogenic H5N1 avian influenza in waterfowl and wild birds in Hong Kong in late 2002. Avian Pathol. 33 (5) 492-505.

Fang, T.S., Lien, L.Y., Cheng, M.C., Tsai, H.J., 2006. Resistance of immunesuppressed pigeons to subtypes H5N2 and H6N1 low pathogenic avian influenza viruses. Avian Dis. 50, 269-272.

Ferro, P.J., Peterson, M.J., Merendino, T., Nelson, M., Lupiani, B., 2010. Comparison of real-time reverse transcription-PCR and virus isolation for estimating prevalence of avian influenza virus in hunter-har- 
vested wild birds at waterfowl wintering grounds along the Texas mid-Gulf Coast (2005-2006 through 2008-2009). Avian Dis. 54, 655659.

Gambaryan, A.S., Piskarev, V.E., Yamskov, I.A., Sakharov, A.M., Tuzikov, A.B., Bovin, N.V., Nifant'ev, N.E., Matrosovich, M.N., 1995. Human influenza virus recognition of oligosaccharides. FEBS Lett. 366, 57-60.

Gronesova, P., Mizakova, A., Betakova, T., 2009. Determination of hemagglutinin and neuraminidase subtypes of avian influenza A viruses in urban pigeons by a new nested RT-PCR. Acta Virol. 53, 213-216.

Guan, Y., Shortridge, K.F., Krauss, S., Chin, P.S., Dyrting, K.C., Ellis, T.M., Webster, R.G., Peiris, M., 2000. H9N2 influenza viruses possessing H5N1-like internal genomes continue to circulate in poultry in Southeastern China. J. Virol. 74 (20) 9372-9380.

Guo, Y.J., Krauss, S., Senne, D.A., Mo, I.P., Lo, K.S., Xiong, X.P., Norwood, M., Shortridge, K.F., Webster, R.G., Guan, Y., 2000. Characterization of the pathogenicity of members of the newly established H9N2 influenza virus lineages in Asia. Virology 267 (2) 279-288.

Hayashi, T., Hiromoto, Y., Chaichoune, K., Patchimasiri, T., Chakritbudsabong, W., Prayoonwon, N., Wiriyarat, W., Parchariyanon, S., Ratanakorn, P., Uchida, Y., Saito, T., 2011a. Host cytokine responses of pigeons infected with highly pathogenic Thai avian influenza viruses of subtype H5N1 isolated from wild birds. PLoS ONE 6 (8) 1-13.

Hayashi, T., Chaichoune, K., Patchimasiri, T., Hiromoto, Y., Kawasaki, Y., Wiriyarat, W., Chakritbudsabong, W., Prayoonwong, N., Chaisilp, N., Parchariyanon, S., Ratanakorn, P., Uchida, Y., Tsuda, T., Saito, T., 2011b. Differential host gene responses in mice infected with two highly pathogenic avian influenza viruses of subtype H5N1 isolated from wild birds in Thailand. Virology 412 (1) 9-18.

Jia, B., 2007. An Infectious Status Survey of H5N1 Highly Pathogenic Avian Influenza Virus in Harbin, The People's Republic of China. (Thesis to Gain the Degree Master of Veterinary Health)Chiang Mai University, Chiang Mai, Thailand and Free University of Berlin, Berlin, Germany.

Jia, B., Shi, J., Li, Y., Shinya, K., Muramoto, Y., Zeng, X., Tian, G., Kawaoka, Y., Chen, H., 2008. Pathogenicity of Chinese H5N1 highly pathogenic avian influenza virus in pigeons. Arch. Virol. 153, 1821-1826.

Kaleta, E.F., Hönicke, A., 2004. Review of the literature on avian influenza A viruses in pigeons and experimental studies on the susceptibility of domestic pigeons to influenza A viruses of the haemagglutinin subtype H7. Dtsch. Tierärztl. Wschr. 111, 453-484.

Kayali, G., El-Sheshney, R., Kutat, M., Kandeil, A.M., Mostafa, A., Ducatez, M.F., McKenzie, P.P., Govorkova, E.A., Nasraa, M.H., Webster, R.G., Webby, R.J., Mohamed, A., 2011. Continuing threat of influenza (H5N1) virus circulation in Egypt. Emerg. Infect. Dis. 17 (12) 2306-2308.

Khawaja, J.Z., Naeem, K., Ahmed, Z., Ahmad, S., 2005. Surveillance of avian influenza viruses in wild birds in areas adjacent to epicentre of an outbreak in Federal Capital Territory of Pakistan. Int. J. Poult. Sci. 4 (1) 39-43.

Kilany, W.H., Arafa, A., Erfan, A.M., Ahmed, M.S., Nawar, A.A., Selim, A.A., Khoulosy, S.G., Hassan, M.K., Aly, M.M., Hafez, H.M., Abdelwhab, E.M., 2010. Isolation of highly pathogenic avian influenza H5N1 from table eggs after vaccinal break in commercial layer flock. Avian Dis. 54 (3) 1115-1119.

Klopfleisch, R., Werner, O., Mundt, E., Harder, T., Teifke, J.P., 2006. Neurotropism of highly pathogenic avian influenza virus A/Chicken/Indonesia/2003 (H5N1) in experimentally infected pigeons (Columbia livia f. domestica). Vet. Pathol. 43, 463-470.

Kohls, A., Lüschow, D., Lierz, M., Hafez, H.M., 2011. Influenza A virus monitoring in urban and free-ranging pigeon populations in Germany, 2006-2008. Avian Dis. 55, 447-450.

Kulak, M.V., Ilinykh, F.A., Zaykovskaya, A.V., Epanchinzeva, A.V., Evstaphiev, I.L., Tovtunec, N.N., Sharshov, K.A., Durimanov, A.G., Penkovskaya, N.A., Shestopalov, A.M., Lerman, A.I., Drozdov, I.G., Swayne, D.E., 2010. Surveillance and identification of influenza A viruses in wild aquatic birds in the Crimea, Ukraine (2006-2008). Avian Dis. 54 (3) 1086-1090.

Lefrançois, T., Hendrikx, P., Ehrhardt, N., Millien, M., Gomez, L., Gouyet, L., Gaidet, N., Gerbier, G., Vachiéry, N., Petitclerc, F., Carasco-Lacombe, C., Pinarello, V., Ahoussou, S., Levesque, A., Gongora, H.V., Trotman, M., 2010. Surveillance of avian influenza in the Caribbean through the Caribbean Animal Health Network: surveillance tools and epidemiologic studies. Avian Dis. 54 (1 Suppl.) 369-373.

Li, J., Cardona, C.J., 2010. Adaptation and transmission of a wild duck avian influenza isolate in chickens. Avian Dis. 54 (1 Suppl) 586-590.

Li, K.S., Guan, Y., Wang, J., Smith, G.J., Xu, K.M., Duan, L., Rahardjo, A.P., Puthavathana, P., Buranathai, C., Nguyen, T.D., Estoepangestie, A.T., Chaisingh, A., Auewarakul, P., Long, H.T., Hanh, N.T., Webby, R.J., Poon, L.L., Chen, H., Shortridge, K.F., Yuen, K.Y., Webster, R.G., Peiris, J.S., 2004. Genesis of a highly pathogenic and potentially pandemic H5N1 influenza virus in eastern Asia. Nature 430 (6996) 209-213.
Li, Q., Zhou, L., Zhou, M., Chen, Z., Li, F., Wu, H., Xiang, N., Chen, E., Tang, F., Wang, D., Meng, L., Hong, Z., Tu, W., Cao, Y., Li, L., Ding, F., Liu, B., Wang, M., Xie, R., Gao, R., Li, X., Bai, T., Zou, S., He, J., Hu, J., Xu, Y., Chai, C., Wang, S., Gao, Y., Jin, L., Zhang, Y., Luo, H., Yu, H., He, J., Li, Q., Wang, X., Gao, L., Pang, X., Liu, G., Yan, Y., Yuan, H., Shu, Y., Yang, W., Wang, Y., Wu, F., Uyeki, T.M., Feng, Z., 2014. Epidemiology of human infections with avian influenza A(H7N9) virus in China. N. Engl. J. Med. 370 (6) 520-532.

Lillehaug, A., Jonassen, C.M., Bergsjø, B., Hofshagen, M., Tharaldsen, J., Nesse, L.L., Handeland, K., 2005. Screening of feral pigeon (Columbia livia), Mallard (Anas platyrhynchos) and Greylag goose (Anser anser) populations for Campylobacter spp., Salmonella spp., avian influenza viruses and avian paramyxoviruses. Acta Vet. Scand. 46, 193-202.

Liu, M., He, S., Walker, D., Zhou, N., Perez, D.R., Mo, B., Li, F., Huang, X., Webster, R.G., Webby, R.J., 2003. The influenza virus gene pool in a poultry market in south central China. Virology 305 (2) 267-275.

Liu, Y., Zhou, J., Yang, H., Yao, W., Bu, W., Yang, B., Song, W., Meng, Y., Lin, J., Han, C., Zhu, J., Ma, Z., Zhao, J., Wang, X., 2007. Susceptibility and transmissibility of pigeons to Asian lineage highly pathogenic avian influenza virus subtype H5N1. Avian Pathol. 36 (6) 461-465.

Liu, Y., Han, C., Wang, X., Lin, J., Ma, M., Shu, Y., Zhou, J., Yang, H., Liang, Q., Guo, C., Zhu, J., Wei, H., Zhao, J., Ma, Z., Pan, J., 2009. Influenza A virus receptors in the respiratory and intestinal tracts of pigeons. Avian Pathol. 38 (4) 263-266.

Mohammadi, A., Masoudian, M., Nemati, Y., Seifi, S., 2010. Serological and RT-PCR assays for detection of avian influenza of domestic pigeons in Kavar area (Fars Province, Iran). Bulgarian J. Vet. Med. 13 (2) 117121.

Motha, J., Gibbons, A.M., Reed, C.E., 1997. A survey for avian paramyxoviruses and influenza viruses in feral pigeons and native birds in New Zealand. N. Z. Vet. J. 45 (5) 215-216.

Moncorgé, O., Mura, M., Barclay, W.S., 2010. Evidence for avian and human host cell factors that affect the activity of influenza virus polymerase. J. Virol. 84 (19) 9978-9986.

Moskophidus, D., Kioussis, D., 1998. Contribution of virus-specific CD8+ cytotoxic $T$ cell to virus clearance or pathogenic manifestations of influenza virus infection in a T cell receptor transgenic mouse model. J. Exp. Med. 188 (2) 223-232.

Nettles, V.F., Wood, J.M., Webster, R.G., 1985. Wildlife surveillance associate with an outbreak of lethal H5N2 avian influenza in domestic poultry. Avian Dis. 29 (3) 733-741.

Nayaran, O., Lang, G., Rouse, B.T., 1969. A new influenza virus infection in turkeys. IV. Experimental susceptibility of domestic birds to virus strain turkey/Ontario/7732/1966. Arch. Ges. Virusforsch. 26, 149165.

Nkwankwo, I.O., Faleke, O.O., Garba, J., 2012. Avian influenza virus infection in apparently healthy domestic birds in Sokoto, Nigeria. Vet. Ital. 48 (3) 309-312.

Avian Influenza (Chapter 2.3.4). Accessible at www.oie.int.

. Accessible at http://www.oie.int/international-standard-setting/terrestrial-code/access-online/

Pandit, P.S., 2008. Avian Influenza Surveillance in Domestic Pigeons Columba livia domestica (Dissertation). Accessible at: http://www.academia.edu/2673285/Avian_Influenza_Surveillance_in_Domestic_Pigeons Columba_livia_domestica.

Panigrahy, B., Senne, D.A., Pedersen, J.C., Shafer, A.L., Pearson, J.E., 1996. Susceptibility of pigeons to avian influenza. Avian Dis. 40, 600-604.

Pant, G.R., Selleck, P.W., 2007. Surveillance for avian influenza in Nepal 2004-2005. Avian Dis. 51 (1 Suppl.) 352-354.

Pantin-Jackwood, M.J., Smith, D.M., Wasilenko, J.L., Spackman, E., 2012. Low pathogenicity avian influenza viruses infect chicken layers by different routes of inoculation. Avian Dis. 56 (2) 276-281.

Perkins, L.E., Swayne, D.E., 2002. Pathogenicity of Hong Kong-origin highly pathogenic avian influenza virus for emus, geese, ducks and pigeons. Avian Dis. 46, 53-63.

Pérez-Ramírez, E., Gerrikagoitia, X., Barral, M., Höfle, U., 2010. Detection of low pathogenic avian influenza viruses in wild birds in Castilla-La Mancha (south central Spain). Vet. Microbiol. 146, 200-208.

Perkins, L.E., Swayne, D.E., 2003. Comparative susceptibility of selected avian and mammalian species to a Hong Kong-origin H5N1 highpathogenicity avian influenza virus. Avian Dis. 47, 956-967.

Peroulis, I., O'Riley, K., 2004. Detection of avian paramyxoviruses and influenza viruses amongst wild bird populations in Victoria? Aust. Vet. J. 82 (1-2) 79-82.

Petersen, H., Matrosovich, M., Pleschka, S., Rautenschlein, S., 2012. Replication and adaptive mutations of low pathogenic avian influenza viruses in tracheal organ cultures of different avian species. PLoS ONE 7 (8) e42260, http://dx.doi.org/10.1371/journal.pone.0042260.

Phonaknguen, R., Chaichoun, K., Wiriyarat, W., Sariya, L., Prayoowong, N., Chaisilp, N., Moonjit, P., Puthavathana, P., Auewarakul, P., Ratanakorn, 
P., Songserm, T., 2013. Minimal susceptibility to highly pathogenic avian influenza H5N1 infection of pigeons (Columba livia) and potential transmission of the virus to comingled domestic chickens. Kasetsart J. Nat. Sci. 47, 720-732.

Pillai, S.P., Saif, Y.M., Lee, C.W., 2010. Detection of influenza A viruses in eggs laid by infected turkeys. Avian Dis. 54 (2) 830-833.

Powell, T.J., Dwyer, D.W., Morgan, T., Hollenbaugh, J.A., Dutton, R.W., 2006. The immune system provides a strong response to even a low exposure to virus. Clin. Immunol. 119, 87-94.

Promkuntod, N., Antarasena, G., Prommuang, P., Prommuang, P., 2006. Isolation of avian influenza virus A subtype H5N1 from internal contents (albumen and allantoic fluid) of Japanese quail (Coturnix coturnix japonica) eggs and oviduct during a natural outbreak. Ann. N.Y. Acad. Sci. 1081, 171-173.

Shell, W., 2004. Experimental infection of pigeons with HPAI H7N7 (The Netherlands 2003 virus). In: Alexander, D.J. (Ed.), Proceedings of the Joint Tenth Annual Meetings of the National Newcastle Disease and Avian Influenza Laboratories of countries of the European Union, 30 September-1 October 2004.

Singsanan-Lamont, J., Robertson, I., Blacksell, S.D., Ellis, T., Fenwick, S., Saengchoowong, S., Suwanpukdee, S., Yongyuttawichai, P., Sariya, L., Prompiram, P., Chaichoun, K., Wiriyarat, W., Pothieng, D., Ratankorn, P., 2011. Virological and molecular epidemiological investigations into the role of wild birds in the epidemiology of influenza A/H5N1 in central Thailand. Vet. Microbiol. 148, 213-218.

Slemons, R.D., Easterday, B.C., 1972. Host response differences among 5 avian species to an influenzavirus-A/turkey/Ontaria/7732/66 (Hav5N?). Bull. World Health Org. 47, 521-525.

Smietanka, K., Minta, Z., Wyrostek, K., Jozwiak, M., Olszewska, M., Domanska-Blicharz, K., Reichert, M., Pikula, A., Habyarimana, A., van den Berg, T., 2011. Susceptibility of pigeons to clade 1 and clade 2.2 highly pathogenic avian influenza H5N1 virus. Avian Dis. 55, 106-112.

Songserm, T., Amonsin, A., Jam-on, R., Sae-Heng, N., Meemak, N., Pariyothorn, N., Payungporn, S., Theamboonlers, A., Poovorawan, Y., 2006. Avian influenza H5N1 in naturally infected domestic cat. Emerg. Infect. Dis. 12 (4) 681-683.

Teske, L., Ryll, M., Rautenschlein, S., 2013. Epidemiological investigations on the role of clinically healthy racing pigeons as a reservoir for avian paramyxovirus-1 and avian influenza virus. Avian Pathol. 42 (6) 557565.

Tong, S., Li, Y., Rivailler, P., Conrardy, C., Castillo, D.A., Chen, L.M., Recuenco, S., Ellison, J.A., Davis, C.T., York, I.A., Turmelle, A.S., Moran, D., Rogers, S., Shi, M., Tao, Y., Weil, M.R., Tang, K., Rowe, L.A., Sammons, S., Xu, X., Frace, M., Lindblade, K.A., Cox, N.J., Anderson, L.J., Rupprecht, C.E., Donis, R.O., 2012. A distinct lineage of influenza A virus from bats. Proc. Natl. Acad. Sci. U.S.A. 109 (11) 4269-4274.

Tong, S., Zhu, X., Li, Y., Shi, M., Zhang, J., Bourjeois, M., Yang, H., Chen, X., Recuenco, S., Gomez, J., Chen, L.M., Johnson, A., Tao, Y., Dreyfus, C., Yu,
W., McBride, R., Carney, P.J., Gilbert, A.T., Chang, J., Guo, Z., Davis, C.T., Paulson, J.C., Stevens, J., Rupprecht, C.E., Holmes, E.C., Wilson, I.A., Donis, R.O., 2013. New World bats harbour diverse influenza A viruses. PLoS Pathog. 9 (10) e1003567.

Verhagen, J.H., Munster, V.J., Majoor, F., Lexmond, P., Vuong, O., Stumpel, J.B., Rimmelzwaan, G.F., Osterhaus, A.D., Schutten, M., Slaterus, R., Fouchier, R.A., 2012. Avian influenza a virus in wild birds in highly urbanized areas. PLoS ONE 7 (6) e38256.

Wasilenko, J.L., Lee, C.W., Sarmento, L., Spackman, E., Kapczynski, D.R., Suarez, D.L., Pantin-Jackwood, M.J., 2008. NP, PB1, and PB2 viral genes contribute to altered replication of H5N1 avian influenza viruses in chickens. Virology 82 (9) 4544-4553.

Werner, O., Starick, E., Teifke, J., Klopfleisch, R., Prajitno, T., Beer, M., Hoffmann, B., Harder, T.C., 2007. Minute excretion of highly pathogenic avian influenza virus A/chicken/Indonesia/2003 (H5N1) from experimentally infected domestic pigeons (Columbia livia) and lack of transmission to sentinel chickens. J. Gen. Virol. 88, 3089-3093.

WHO, 2013. Cumulative Number of Confirmed Human Cases for Avian Influenza A(H5N1) Reported to WHO, 2003-2013. http:// www.who.int/influenza/human_animal_interface/ EN_GIP_20130604CumulativeNumberH5N1 cases.pdf.

. Accessible at http://www.who.int/csr/resources/publications/influenza/ en/whocdscsrncs20025rev.pdf.

Yamamoto, Y., Nakamura, K., Yamada, M., Mase, M., 2010. Comparative pathology of chickens and domestic ducks experimentally infected with highly pathogenic avian influenza viruses (H5N1) isolated in Japan in 2007 and 2008. JARQ 44 (1) 73-80.

Yamamoto, Y., Nakamura, K., Yamada, M., Mase, M., 2012. Limited susceptibility of pigeons experimentally inoculated with H5N1 highly pathogenic avian influenza viruses. J. Vet. Med. Sci. 74 (2) 205208.

Yu, Z., Song, Y., Zhou, H., Xu, X., Hu, Q., Wu, H., Zhang, A., Zhou, Y., Chen, J., Dan, H., Luo, Q., Li, X., Chen, H., Ji, M., 2007. Avian influenza (H5N1) virus in waterfowl and chickens, Central China. Emerg. Infect. Dis. 13 (5) $772-775$.

Zhang, Q., Shi, J., Deng, G., Guo, J., Zeng, X., He, X., Kong, H., Gu, C., Li, J., Liu, J., Wang, G., Chen, Y., Liu, L., Liang, L., Li, Y., Fan, J., Wang, F., Li, W., Guan, L., Li, Q., Yang, H., Chen, P., Jiang, P., Jiang Li Guan, Y., Xin, X., Jiang, Y., Tian, G., Wang, X., Qiao, C., Li, C., Bu, Z., Chen, H., 2013. H7N9 influenza viruses are transmissible in ferrets by respiratory droplet. Science 341, 410-414.

Zhou, J.-P., Ge, F.-F., Liu, J., Ju, H.-B., Yang, D.-Q., Wang, J., Zhang, W.-Y., Liu, P.-H., 2012. Epidemiological survey and genetic evolution of H9 subtype influenza viruses in Shanghai, China, from 2006 to 2010. Arch. Virol. 157, 1193-1198.

Zupancic, Z., Ugrcic, I., Jelavic, V., Ivesa-Petricevic, S., Greguric, J., Jukic, B., Smerdel, S., 1986. Antibodies for human influenza type A virus in bird sera. Vet. Arh. 56, 217-225. 